Copyright (C) 2021 University of Bucharest Printed in Romania. All rights reserved ISSN print: 1224-5984

ISSN online: $2248-3942$
Rom Biotechnol Lett. 2021; 26(3): 2594-2605 doi: $10.25083 / \mathrm{rbl} / 26.3 / 2594.2605$

Received for publication, April, 28, 2020

Accepted, December, 9, 2020

Original paper

\title{
Preliminary evaluation of vegetal extract characteristics from spontaneous flora of Moldova area (Romania)
}

\author{
GABRIEL MIHAITA DARABAN ${ }^{1}$, CARMEN ZAHARIA ${ }^{\mathbf{1}^{*}}$, DANIELA SUTEU ${ }^{\mathbf{1}}$, \\ ADRIAN PUITEL ${ }^{1}$, RAMONA ELENA TATARU-FARMUS ${ }^{1}$, MARINELA BADEANU ${ }^{2}$ \\ 1"Gheorghe Asachi” Technical University of Iasi, "Cristofor Simionescu” Faculty of Chemical Engineering and \\ Environmental Protection, 73A Prof. Dr. Docent D. Mangeron Blvd, 700050, Iasi, Romania \\ 2"Ion Ionescu de la Brazi" University of Agricultural Sciences and Veterinary Medicine of Iasi, 29 Mihail \\ Sadoveanu str., 700490, Iasi, Romania
}

\begin{abstract}
Two classical methods were applied for preparation of four plant extracts, i.e. heat reflux extraction and maceration, exactly for wormwood (Artemisia absinthium), yarrow (Achillea millefolium), oregano (Origanum vulgare) and primrose (Primula veris), plants from the spontaneous flora of Moldova area (Romania). The prepared extracts were preliminarily characterized by some known physical-chemical analytical methods used to evaluate various quality indicators of plant extracts (e.g. total polyphenols and flavonoids concentrations, density, viscosity) as well as comparative analysis of their UV-Vis and FTIR spectra. These vegetal extracts are non-toxic, and may have insecticide effect on the field of agricultural culture and storage pests.
\end{abstract}

Keywords Alcoholic extraction, flavonoids, FTIR/UV-Vis spectra, polyphenols, spontaneous flora, plant extract.

To cite this article: DARABAN GM, ZAHARIA C, SUTEU D, PUITEL A, TATARUFARMUS RE, BADEANU M. Preliminary evaluation of vegetal extract characteristics from spontaneous flora of Moldova area (Romania). Rom Biotechnol Lett. 2021; 26(3): 2594-2605. DOI: $10.25083 / \mathrm{rbl} / 26.3 / 2594.2605$ $\begin{aligned} \lambda \text { *Corresponding author: } & \text { CARMEN ZAHARIA, "Gheorghe Asachi” Technical University of Iasi, "Cristofor } \\ & \text { Simionescu" Faculty of Chemical Engineering and Environmental Protection, 73A Prof. }\end{aligned}$ Dr. Docent D. Mangeron Blvd, 700050 Iasi, Romania; Tel.: +40232-278683 int. 2175, Fax: +40232-271311

E-mail: czah@ch.tuiasi.ro 


\section{Introduction}

The industrial development, evolution of humanity, and/or climate changes lead to new perceptions or/and changes of some thinking systems related to sustainable development. In this context, the interest in numerous diverse fields and life sciences has increasingly returned to the nature, high valorisation of raw materials offered by the environment, avoiding as much as possible an accentuated use of chemical synthesis products. Many scientific studies were highlighted the existence of various biologically active compounds in vegetal extracts, helpfully in the domain of foods, cosmetics, pharmacy industry, or phytosanitation (FIERASCU et al, 2017 [1]; IGNAT et al, 2011 [2]; MOCAN et al, 2018 [3]; PRUTEANU et al, 2018 [4]).

An insufficiently studied and exploited research direction is represented today by the utilization of the active compounds from plants in the agriculture field, especially for the management of weeds and dangerous species in crops and storing locations/deposits. Although the chemical pesticides have demonstrated satisfactory results/protective effects, their repetitive and intensive use can lead to various consequences such as: insects resistance development, quality deterioration of raw vegetal materials and animals' meat, food quality reduction and, finally, affectation of the population health.

Numerous biologically active compounds in plants have been identified as having high efficacy on plant pests through various action mechanisms/paths and low toxicity to humans, which has increased interest in using plant extracts as biopesticides in a stabilized form (BRZOZOWSKI and MAZOUREK, 2018 [5]; CHANDLER et al, 2011 [6]; DAYAN et al, 2009 [7]; GILL and GARG, 2014 [8]; GUPTA and DIKSHIT, 2010 [9]; MAZID et al, 2011 [10]). Thus, biopesticides could be regarded as a potential replacement for chemical pesticides.

Our previous studies have highlighted that, from all studied plants of Bucovina spontaneous flora (Suceava region, Romania), only a number of eleven plants used to prepare plant extracts (initially, by maceration) have showed bio-insecticide action on crop pests (Leptinotarsa decemlineata) or deposit (Acanthoscelides obtectus) (DARABAN et al, 2018 [11]; DARABAN et al, 2018 [12]; DARABAN et al, 2020 [13]). The hierarchy of these plants after the bio-insecticide effect led to the identification of four plants to be proposed for this study which had relative strong effects for the two types of pests.

In this context, the aim of this paper was to obtain and characterize the plant extracts from spontaneous flora of Bucovina region (Romania) for the obtaining of non-toxic vegetal extracts, which demonstrated bioinsecticide effect on the pests field using two classical methods: (i) heat reflux extraction (Soxhlet method) and (ii) maceration. The obtained extracts were preliminarily characterized by determination of some quality indicators (total polyphenols and flavonoids concentrations, density and viscosity) and also by their exhaustive analysis (UV-Vis and FTIR spectra interpretation).

\section{Experimental}

\section{Plant materials and chemicals}

The whole plants (stem, leaves and flowers) of Artemisia absinthium, Achillea millefolium, Origanum vulgare and Primula veris were collected from Siret Valley, Suceava region (Romania), in the summer of 2017 and 2018 years. The plants were identified and certified by a team of experts from "Ion Ionescu de la Brazi" University of Agricultural Sciences and Veterinary Medicine of Iasi, Faculty of Horticulture. Plant drying was done in a well-ventilated space that does not come in direct contact with sunlight. The stems, flowers and leaves of the dried plants were ground using a laboratory mill. The obtained powders were stored in a dry laboratory container. The humidity determination of the dried plant powders was done by the drying method using a thermobalance RADWAG type (AC 230 V/400W, 50Hz). All used chemical reagents were of analytical quality (Sigma Aldrich, Merck Co.).

\section{Plant extract preparation}

The classical methods of liquid-solid extraction (e.g., maceration and heat reflux extraction with Soxhlet installation) were done with $96 \%$ ethyl alcohol, solvent in accordance with the imposed requirements of the agriculture and the food industry. The recommended amount of plant powder (5-50 g) was separately introduced in adequate volume $(50-1000 \mathrm{~mL})$ of solvent(s) corresponding to the established phases ratios (1/10, 1/15 and/or 1/20). A batch extraction (maceration) at room temperature $\left(20-23^{\circ} \mathrm{C}\right)$ for 9 days and a reflux extraction in the Soxhlet installation of $45 \mathrm{~min}, 1 \mathrm{~h}$ and $2 \mathrm{~h}$ were done. Each plant extract was separated, and stored in cold and dark room space until further use for its characterization and testing of insecticide properties.

\section{Determination of extraction degree}

Samples of vegetal extract $(5 \mathrm{~mL})$ were evaporated to dryness at constant temperature (up to $60^{\circ} \mathrm{C}$ ) using a thermostatic oven, Poleko SLW53 model. The extraction yield was determined with Eq.(1) (DARABAN et al, 2020 [13]): 


$$
\eta \%=\frac{\mathrm{m}_{\text {residue }} \cdot \mathrm{V}_{\text {extract }}}{\mathrm{n}_{\text {extract }} \cdot \mathrm{m}_{\text {solidsample }}} \cdot 100
$$

where, $m_{\text {residue }}$ is the amount of the residue remained after the evaporation to dryness, $(\mathrm{g}) ; V_{\text {extract }}$ - the plant extract volume used at evaporation to dryness, $(\mathrm{mL})$; $n_{\text {extract }}$ - the total plant extract volume obtained after the liquid-solid extraction, $(\mathrm{mL}) ; m_{\text {solid sample }}$ - the amount of vegetal sample used in the extraction process $(\mathrm{g})$.

\section{Chemical composition of plant extracts by UV-VIS and FTIR analysis}

The UV-Vis spectrophotometer, Jasco V-550 model, was used to register the spectra of all prepared plant extract samples in the range of 200-800 nm. Also, FTIR spectra were recorded on solid samples of dried plant powder, before and after extraction, in $\mathrm{KBr}$ pellets by means of a FTIR BioRad FTS 2000 spectrometer, in range of $400-4000 \mathrm{~cm}^{-1}$.

The quantitative characterization of the plant extracts has consisted of a few types of physical-chemical analyses:

- The content of total polyphenols was evaluated using the Folin-Ciocalteu method (PAVUN et al, 2018 [14]. The same standard methodology was applied for different concentrations of gallic acid to obtain the standard calibration curve. The results were expressed in $\mu \mathrm{g}$ of gallic acid equivalent (GAE) per g ( $\mu \mathrm{g}$ GAE/g) taking into account the sample dilution. All analyses were performed in duplicates

- The content of flavonoids was determined using the spectrophotometer-based method with $2 \% \quad \mathrm{AlCl}_{3}$ solution in methanol medium [13]. The results were expressed in $\mathrm{mg}$ or $\mu \mathrm{g}$ of quercitin equivalent (QE) per g (mg QE/g) taking into account the sample dilution. The analyses were performed in duplicates.

- The density was determined by using the gravimetric method and expressed in $\mathrm{g} / \mathrm{cm}^{3}$.

- The viscosity was determined by using the Ubbelode method related to water or ethanol as reference fluids/liquids (TATARU-FARMUS et al, 2007 [15]).

\section{Results and Discussion}

\section{Qualitative characterization of all plant powders}

The plant powders used in all experimental studies were prepared by grinding the entire plant. Firstly, the vegetal powders were analysed for determination of their initial humidity, and FTIR spectra. The plant humidity (\%) was of 8.21 for Artemisia absinthium; 7.5 for Achillea millefolium; 7.44 for Origanum vulgare and 7.89 for Primula veris. The FTIR spectra allowed the identification of the characteristic functional groups for the main compounds from the composition of each plant powder. Secondly, these spectra were compared with the plant powder spectra recorded after solid-liquid extraction, for emphasizing of the effect of extraction process type, and collection of preliminary information about the nature/type of extracted compounds.

\section{Determination of extraction degree}

The extraction efficiency by the two studied methods is determined in all experimental cases, considering especially the selected working methodology, extraction conditions and plant type. Some selected results are presented in Figure 1 and Table 1. For all plant extracts, residues were obtained after the complete evaporation of $5 \mathrm{~mL}$ of plant extract sample in the thermostatic oven (at the constant temperature of $60^{\circ} \mathrm{C}$ ).

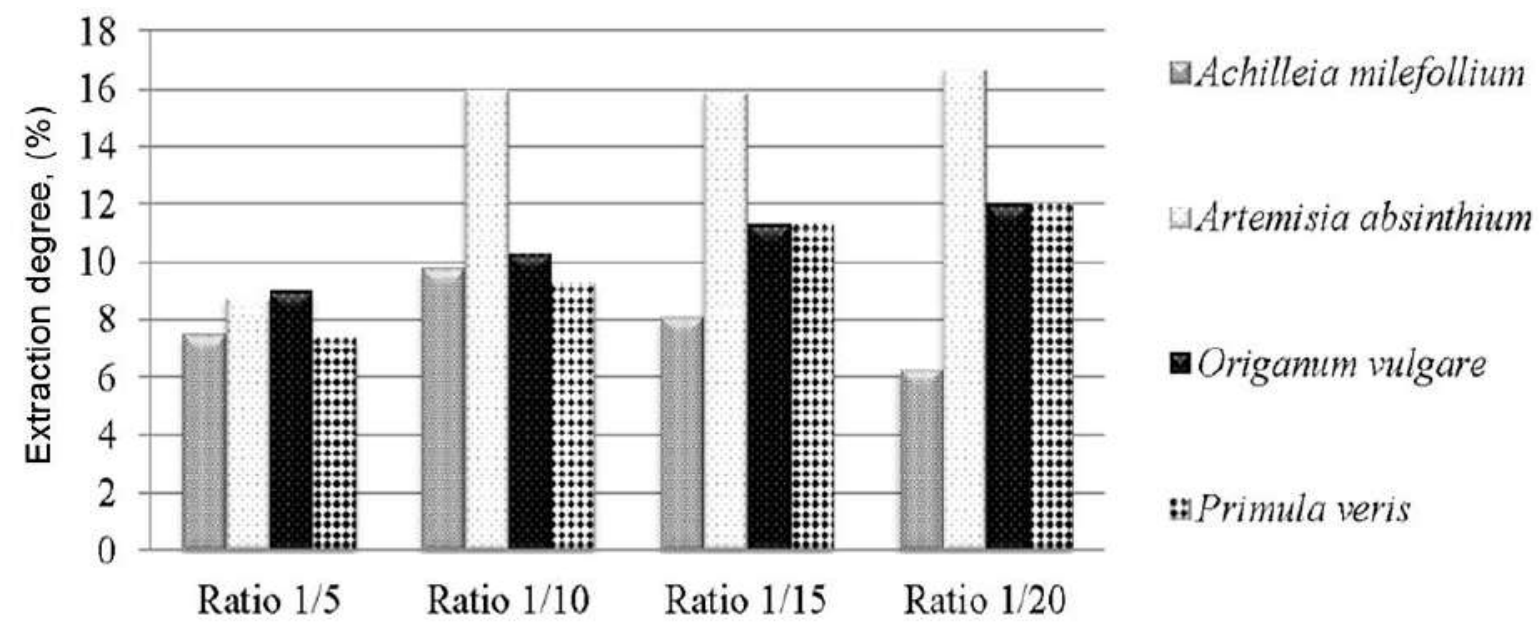

Figure 1. Degree of extraction through the maceration $\left(20^{\circ} \mathrm{C}\right.$ and 9 days $)$. 
Table 1. Degree of extraction through the Soxhlet reflux extraction

\begin{tabular}{|c|c|c|c|c|c|}
\hline \multirow{2}{*}{$\begin{array}{c}\text { Reflux } \begin{array}{c}\text { time } \\
(\text { min })\end{array} \\
\text { solid/liquid }\end{array}$} & \begin{tabular}{c} 
Ratio \\
\cline { 3 - 6 }
\end{tabular} & $\begin{array}{c}\text { Artemisia } \\
\text { absinthium }\end{array}$ & $\begin{array}{c}\text { Achillea } \\
\text { millefolium }\end{array}$ & $\begin{array}{c}\text { Origanum } \\
\text { vulgare }\end{array}$ & $\begin{array}{c}\text { Primula } \\
\text { veris }\end{array}$ \\
\cline { 3 - 6 } & & $(\%)$ & $(\%)$ & $(\%)$ & $(\%)$ \\
\hline \multirow{3}{*}{45} & $1 / 10$ & 8.16 & 12.77 & 2.92 & 10.33 \\
\cline { 2 - 6 } & $1 / 15$ & 12.79 & 14.02 & 5.16 & 6.30 \\
\cline { 2 - 6 } & $1 / 20$ & 11.00 & 14.75 & 3.02 & 10.64 \\
\hline \multirow{2}{*}{60} & $1 / 10$ & 14.04 & 13.91 & 7.37 & 5.31 \\
\cline { 2 - 6 } & $1 / 15$ & 17.80 & 14.97 & 5.54 & 8.51 \\
\cline { 2 - 6 } & $1 / 20$ & 16.46 & 17.66 & 7.03 & 12.09 \\
\hline \multirow{2}{*}{120} & $1 / 10$ & 9.89 & 14.05 & 7.54 & 15.03 \\
\cline { 2 - 6 } & $1 / 15$ & 17.90 & 12.43 & 14.11 & 9.54 \\
\cline { 2 - 6 } & $1 / 20$ & 18.24 & 15.12 & 8.94 & 13.75 \\
\hline
\end{tabular}

The analysis of data from Figure 1 and Table 1 concludes that the extraction depends of the plant type, extraction time and solid/liquid ratio. The efficiency of Artemisia absinthium macerate preparation had appropriate values in the case of solid/liquid ratios of $1 / 10$ and $1 / 15$, and only low increase at $1 / 20$. For Origanum vulgare and Achillea millefolium, good extraction results were registered at $1 / 20$ ratio followed by the extraction at 1/15 ratio, and for Primula veris, similar results were obtained at $1 / 15$ and $1 / 20$ ratios. The degree of extraction by using the heat reflux extraction with Soxhlet installation depends on both ratio of solid/liquid phases and reflux time. Thus, the same extraction efficiency for all tested reflux times was obtained at $1 / 10$ ratio in the case of Artemisia absinthium, Achillea millefolium and Primula veris, and the optimal ratios for all tested times are of $1 / 10$ and 1/15 in the case of Origanum vulgare. Overall, Achillea millefolium has the best extraction behaviour followed by Artemisia absinthium and Primula veris.

\section{Quantitative characterization of the vegetal extract \\ Determination of the total polyphenolic compounds} and flavonoids concentration

The results of all experiments performed in duplicate are presented in Tables 2 and 3.

Table 2. The total polyphenols and flavonoids concentration of plant extract prepared by the maceration

\begin{tabular}{|c|c|c|}
\hline Plant type & $\boldsymbol{C}_{\text {polyphenols }}(\boldsymbol{\mu g} / \boldsymbol{g})$ & $\boldsymbol{C}_{\text {flavonoids }}(\boldsymbol{m g} \mathbf{g})$ \\
\hline Artemisia absinthium & 1.62 & 4.53 \\
\hline Achillea millefolium & 1.57 & 3.57 \\
\hline Origanum vulgare & 1.82 & 1.49 \\
\hline Primula veris & 1.99 & 3.55 \\
\hline
\end{tabular}

Table 3. The total polyphenols and flavonoids concentration of plant extract prepared by the Soxhlet reflux extraction

\begin{tabular}{|c|c|c|c|c|c|c|c|c|c|}
\hline \multirow{3}{*}{$\begin{array}{l}\text { Reflux } \\
\text { time } \\
\text { (min) }\end{array}$} & \multirow{3}{*}{$\begin{array}{c}\text { Solid/ } \\
\text { Liquid } \\
\text { Ratio }\end{array}$} & \multicolumn{8}{|c|}{ Plant type } \\
\hline & & \multicolumn{2}{|c|}{$\begin{array}{l}\text { Artemisia } \\
\text { absinthi }\end{array}$} & \multicolumn{2}{|c|}{$\begin{array}{c}\text { Achillea } \\
\text { millefolium }\end{array}$} & \multicolumn{2}{|c|}{$\begin{array}{c}\text { Origanum } \\
\text { vulgare }\end{array}$} & \multicolumn{2}{|c|}{$\begin{array}{l}\text { Primula } \\
\text { veris }\end{array}$} \\
\hline & & $\begin{array}{c}C_{\text {polyphenols }} \\
(\mu \mathrm{g} / \mathrm{g})\end{array}$ & $\begin{array}{c}C_{\text {flavonoids }} \\
(\mu \mathrm{g} / \mathrm{g})\end{array}$ & $\begin{array}{c}C_{\text {polyphenols }} \\
(\mu \mathrm{g} / \mathrm{g})\end{array}$ & $\begin{array}{c}C_{\text {flavonoids }} \\
(\mu \mathrm{g} / \mathrm{g})\end{array}$ & $\begin{array}{c}C_{\text {polyphenols }} \\
(\mu \mathrm{g} / \mathrm{g})\end{array}$ & $\begin{array}{c}C_{\text {flavonoids }} \\
(\mu \mathrm{g} / \mathrm{g})\end{array}$ & $\begin{array}{c}C_{\text {polyphenol }} \\
(\mu \mathrm{g} / \mathrm{g})\end{array}$ & $\begin{array}{c}C_{\text {flavonoids }} \\
(\mu \mathrm{g} / \mathrm{g})\end{array}$ \\
\hline \multirow[t]{3}{*}{45} & $1 / 10$ & 0.978 & $5,314.86$ & 1.558 & $11,512.05$ & 0.988 & $1,130.41$ & 1.066 & $8,428.49$ \\
\hline & $1 / 15$ & 1.149 & $8,888.89$ & 1.102 & $5,443.14$ & 1.149 & $1,894.18$ & 0.723 & $3,691.03$ \\
\hline & $1 / 20$ & 0.800 & $1,947.04$ & 1.019 & $4,323.70$ & 1.037 & $0,879.28$ & 0.791 & $4,716.15$ \\
\hline \multirow[t]{3}{*}{60} & $1 / 10$ & 1.262 & $5,400.37$ & 1.274 & $7,666.91$ & 1.340 & $3,196.35$ & 0.917 & $6,534.53$ \\
\hline & $1 / 15$ & 1.133 & $5,431.03$ & 1.135 & $5,064.52$ & 1.207 & $1,909.07$ & 0.902 & $5,273.89$ \\
\hline & $1 / 20$ & 1.009 & $2,323.68$ & 0.538 & $1,670.23$ & 1.272 & $2,121.99$ & 0.842 & $4,971.61$ \\
\hline \multirow[t]{3}{*}{120} & $1 / 10$ & 1.129 & $10,457.3$ & 1.347 & $9,183.87$ & 1.415 & $3,381.28$ & 1.494 & $12,404.74$ \\
\hline & $1 / 15$ & 0.898 & $6,531.04$ & 0.958 & $6,707.25$ & 1.384 & $4,851.94$ & 1.232 & $6,128.73$ \\
\hline & $1 / 20$ & 0.902 & $7,788.21$ & 1.080 & $5,018.22$ & 1.237 & $1,781.09$ & 0.938 & $6,938.19$ \\
\hline
\end{tabular}


The data analysis from Tables 2 and 3 showed that the determined values are in agreement with the values of extraction efficiencies presented in Figure 1 and Table 1, the highest content of compounds being observed in the case of extraction processes characterized by the best value of the degree of extraction. Also, it shows that the concentration of flavonoids, regardless to the extraction method used, is superior to that of polyphenols. This finding leads to the idea that the biological active compounds may be found in this category of extracted compounds, which must be further individually identified.

\section{Physical-chemical characterization of plant extracts prepared by the heat reflux extraction}

The prepared alcoholic extracts had a greenish colour and a characteristic alcoholic smell, and the initial plant flavour was kept in a certain proportion. To these plant extracts, a series of physical characteristics required for subsequent technological consideration were determined, mainly the density (Table 4) and viscosity (Figure 2).

Table 4. The density values of prepared plant extracts

\begin{tabular}{|l|c|c|c|c|c|}
\hline \multirow{2}{*}{$\begin{array}{c}\text { Type of } \\
\text { extraction }\end{array}$} & \multicolumn{4}{|c|}{ Plant extract density, $\left(\mathbf{g} / \mathbf{c m}^{3}\right)$} & $\begin{array}{c}\text { Ethanol (96\%) } \\
\text { density, }\left(\mathbf{g} / \mathbf{c m}^{3}\right)\end{array}$ \\
\cline { 2 - 5 } & $\begin{array}{c}\text { Artemisia } \\
\text { absinthium }\end{array}$ & $\begin{array}{c}\text { Achillea } \\
\text { milefolium }\end{array}$ & $\begin{array}{c}\text { Origanum } \\
\text { vulgare }\end{array}$ & $\begin{array}{c}\text { Primula } \\
\text { veris }\end{array}$ & \multirow{2}{*}{0.7894} \\
\cline { 1 - 5 } Maceration & 0.686 & 0.582 & 0.672 & 0.610 & \\
\cline { 1 - 5 } Reflux extraction & 0.808 & 0.737 & 0.775 & 0.815 & \\
\hline
\end{tabular}

The determination of viscosity was performed using the Ubbelode methodology (TATARU-FARMUS et al,
2007 [15]; SHEN et al, 2015 [16]) related to water and ethylic alcohol (Figure 2).

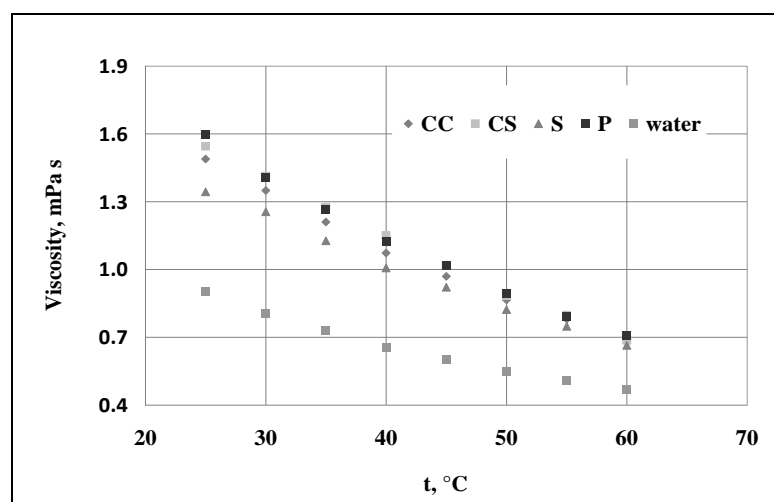

(a)

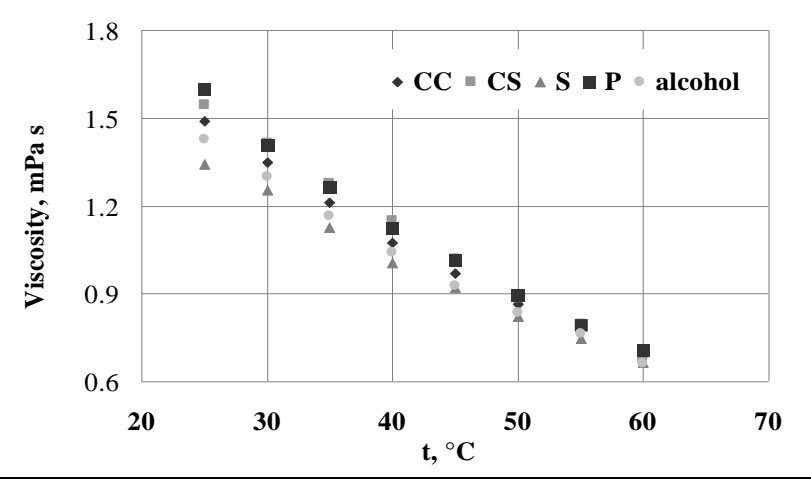

(b)

Figure 2. Viscosity values related to water (a) and ethylic alcohol (b).

The experimental results represented in Figure 2 indicate the net differences between the viscosity values of plant extracts and water $(\boldsymbol{a})$, and the appropriate values in the case of ethanol $(\boldsymbol{b})$. The variation range of viscosity for the studied plant extracts was of 1.340-1.597 mPas at $25^{\circ} \mathrm{C}$ and $0.66-0.71 \mathrm{mPa}$ s at $60^{\circ} \mathrm{C}$. Already known information about the viscosity variation behaviour with the temperature is confirmed meaning the absolute viscosity of prepared plant extracts decreases with the temperature increasing.
UV-Vis and FTIR spectra analysis of plant extracts by heat reflux extraction

The qualitative and quantitative information previously presented permit to conclude that the alcoholic extraction by Soxhlet heat reflux method took place with higher efficiency, and the amount of extracted biological active compounds was net superior to the alcoholic maceration. From this reason, only the plant extracts prepared in the Soxhlet installation were further analysed. The UV-Vis spectra are presented in Figure 3. 

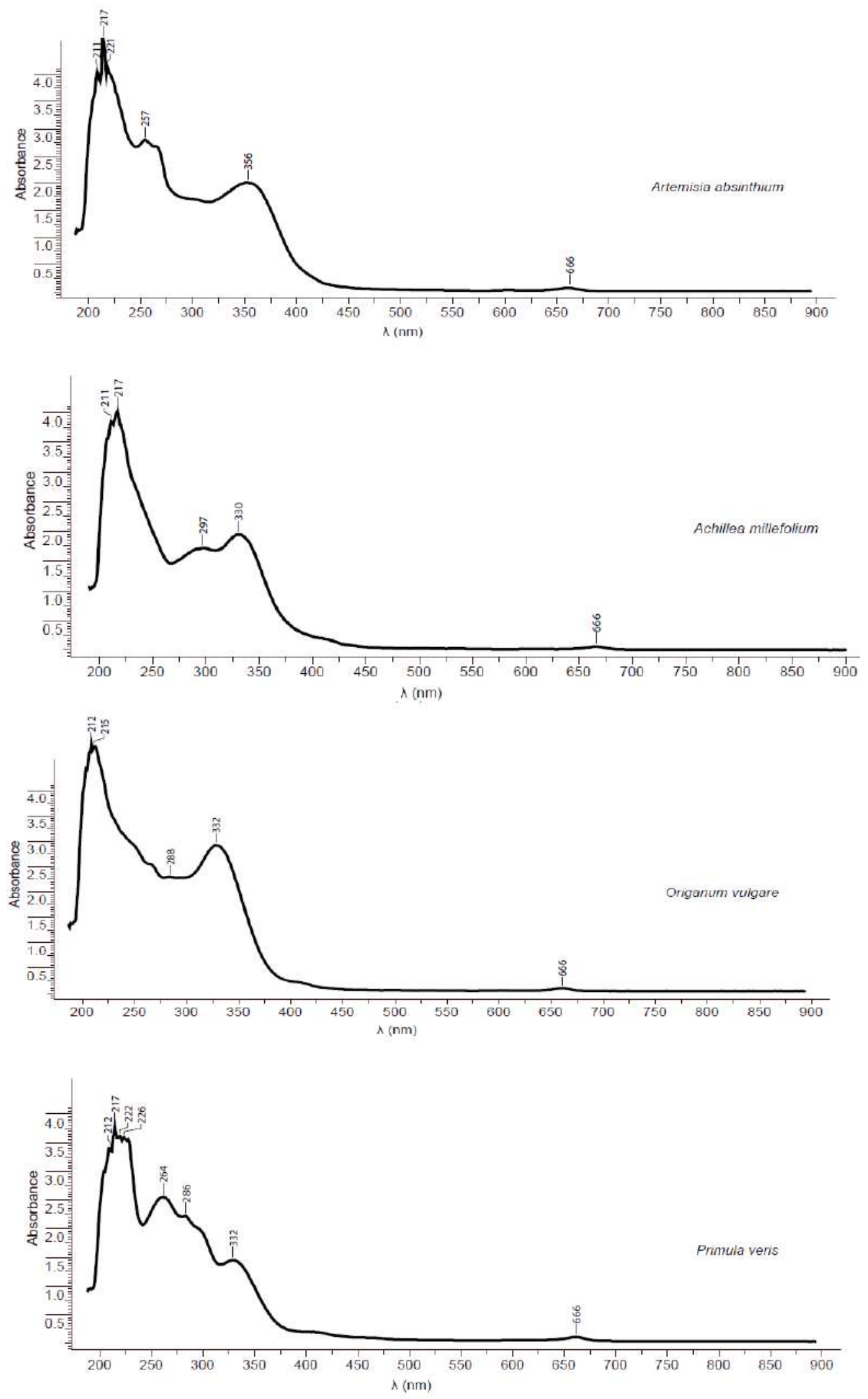

Figure 3. UV-Vis spectra of plant extracts prepared by heat reflux extraction.

The UV-Vis spectra analysis of alcoholic plant extracts can offer a series of preliminary information related to the nature of extracted compounds, e.g., compounds with double bonds in the range of 220 $240 \mathrm{~nm}$, or with triple bonds at 260-280 nm. According with previous quantitative analyses can be underlined 
that a general characteristic of these plant extracts is represented by the emphasizing of a high content of polyphenols and flavonoids (responsible in principal of the antibacterial action), but especially of flavonoids in a few cases.

The scientific literature underlines the fact that in the typical UV-Vis spectra of flavonoids (220-600 nm) are highlighted two maximal peaks: one in the interval of 220-280 nm (characteristic to Band II which supposes the A-ring behaviours) and other in the interval of 330-550 nm (proper to Band I which demonstrates substitution on the B-ring) (BRUCE, 1998 [17]; SPIRIDON et al, 2011 [18]; HARNLY et al, 2007 [19]; ALEIXANDRE-TUDO et al, 2019 [20]). Together with flavonoids exist also a few consistent amounts of other types of phenolic acids (Table 5) and also rests of chlorophyll (666 nm). The vegetal extracts are characterized by the presence of some common compounds but also a few specific compounds, e.g. at $366 \mathrm{~nm}$ in Artemisia absinthium due to phenolic acids or flavonoids; at $297 \mathrm{~nm}$ in Achillea milefolium due to trienes or flavonoids; at $288 \mathrm{~nm}$ in Origanum vulgare due to trienes or flavanones, or at 226 , 264, $286 \mathrm{~nm}$ in Primula veris due to dienes or/and flavonoids which can justify different behaviours in their anti-insecticide action.

The FTIR spectra were registered for the residues (by complete evaporation at constant temperature of $60^{\circ} \mathrm{C}$ ) obtained from each alcoholic plant extract prepared by Soxhlet heat reflux extraction methodology. The obtained FTIR spectra are illustrated in Figure 4.

Table 5. UV-Vis characteristics of the plant extracts

\begin{tabular}{|c|c|c|}
\hline Plant type & $\lambda_{\max }(n m)$ & Possible compounds \\
\hline $\begin{array}{l}\text { Artemisia } \\
\text { absinthium }\end{array}$ & $\begin{array}{l}211,217,221,257, \\
366,666\end{array}$ & \multirow{4}{*}{$\begin{array}{l}\text { ursolic acid }(210 \mathrm{~nm}) \text {; rosmarinic acid } \\
(218 \mathrm{~nm}, 330 \mathrm{~nm}) \text {; ferulic acid }(214 \mathrm{~nm} \text {, } \\
325 \mathrm{~nm}) \text {, chlorogenic acid }(218 \mathrm{~nm}, 325 \mathrm{~nm}) \text {; } \\
\text { p-coumaric acid }(224 \mathrm{~nm}, 309 \mathrm{~nm}) \text {; catechins } \\
(210 \mathrm{~nm}, 278 \mathrm{~nm}, 280 \mathrm{~nm}) \text {; luteolin }(265 \mathrm{~nm} \text {, } \\
330 \mathrm{~nm}) \text {; flavanones }(285 \mathrm{~nm}, 320-330 \mathrm{~nm}) \text {; } \\
\text { quercetin }(256 \mathrm{~nm}, 354 \mathrm{~nm}) \text {; kaempferol } \\
(256 \mathrm{~nm}, 265 \mathrm{~nm}, 272 \mathrm{~nm}, 354 \mathrm{~nm}) \text {; }\end{array}$} \\
\hline $\begin{array}{l}\text { Achillea } \\
\text { milefolium }\end{array}$ & $\begin{array}{l}211,217,297,330, \\
666\end{array}$ & \\
\hline $\begin{array}{l}\text { Origanum } \\
\text { vulgare }\end{array}$ & $\begin{array}{l}212,215,288,332, \\
666\end{array}$ & \\
\hline $\begin{array}{l}\text { Primula } \\
\text { veris }\end{array}$ & $\begin{array}{l}212,217,222,226, \\
264,286,332,666\end{array}$ & \\
\hline
\end{tabular}
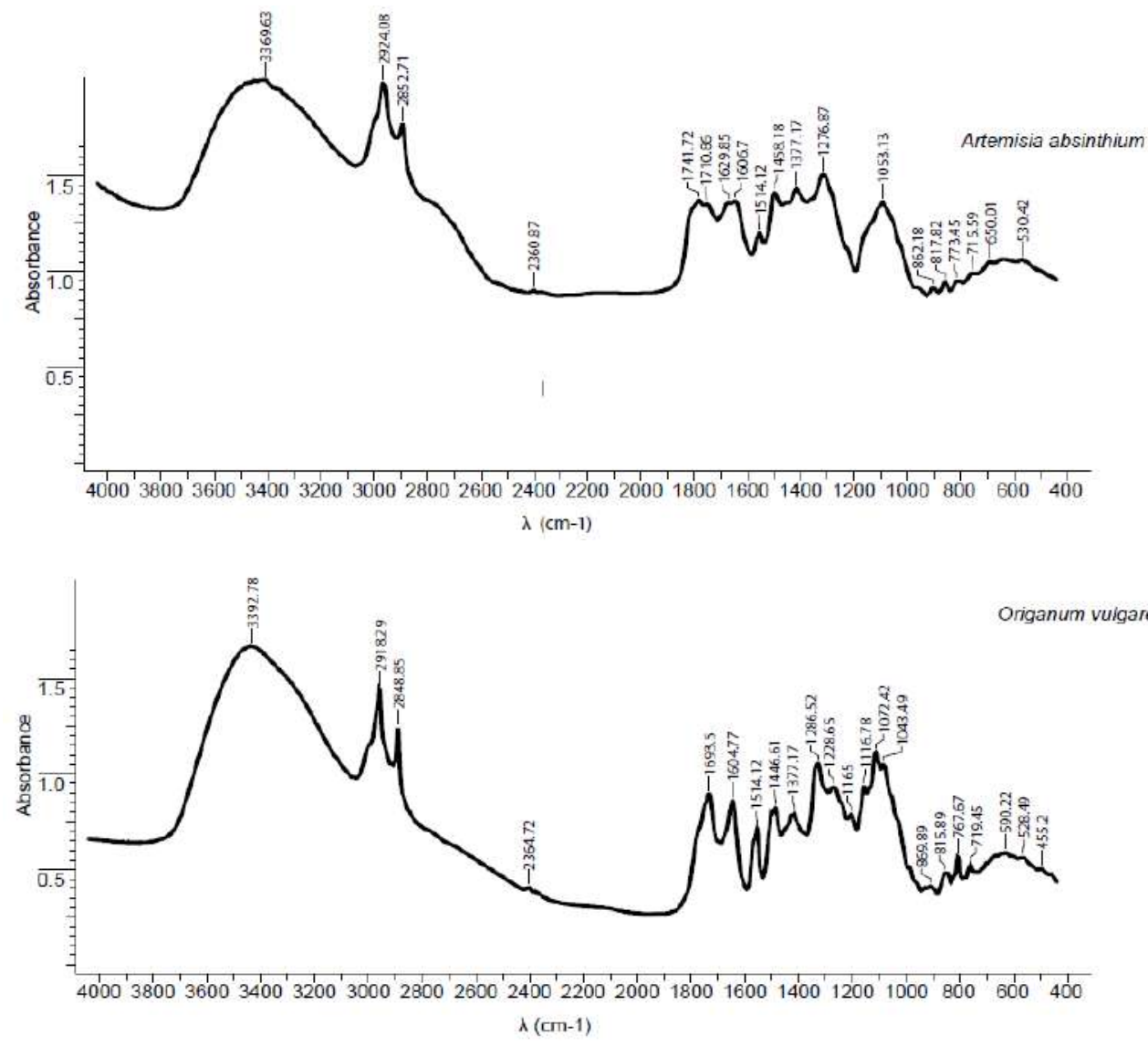

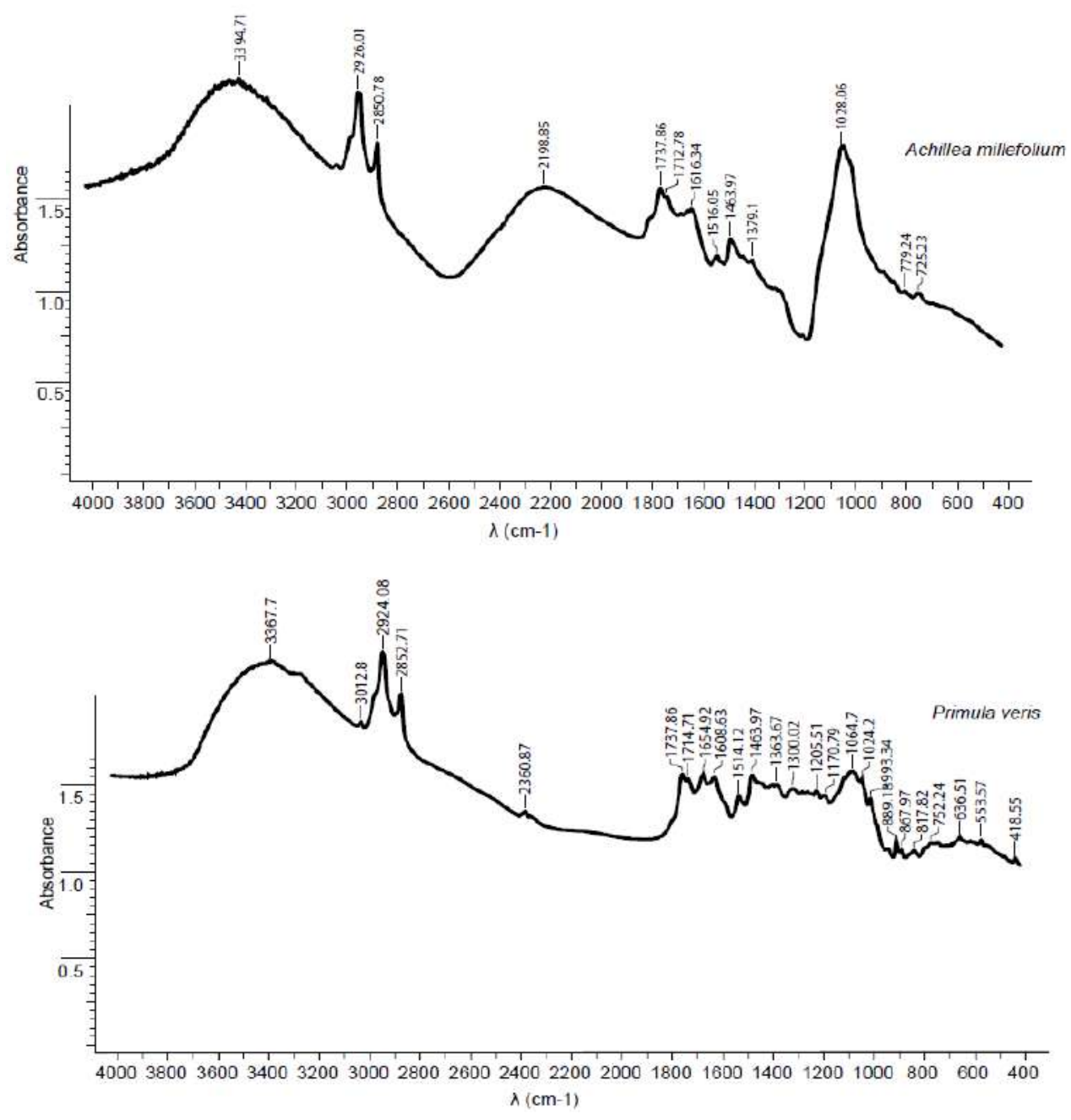

Figure 4. FTIR spectra of residues obtained by evaporation $\left(60^{\circ} \mathrm{C}\right)$ of plant extracts prepared by heat reflux extraction. Artemisia absinthium: phases ratio $=1 / 20$, extraction time $=2 \mathrm{~h} ;$ Origanum vulgare: phases ratio $=1 / 15$, extraction time $=2 \mathrm{~h} ;$ Achillea millefolium: phases ratio $=1 / 20$, extraction time $=1 \mathrm{~h}$; Primula veris: phases retio $=1 / 10$, extraction time $=2 \mathrm{~h}$;

For these FTIR spectra of dried residues obtained by complete evaporation of alcoholic plant extracts, a series of characteristic absorption peaks remarks for the extinction vibrations $\left(\sim 3360-3400 \mathrm{~cm}^{-1}\right)$, or deformation vibrations $\left(\sim 1460 \mathrm{~cm}^{-1} ; 1380 \mathrm{~cm}^{-1}\right)$ of $\mathrm{OH}$ alcoholic, or phenolic groups, vibrations of $\mathrm{CH}$ bond associated to methylene or ethylene groups $\left(\sim 2918 \mathrm{~cm}^{-1} ; \sim 2850 \mathrm{~cm}^{-1}\right)$, vibrations of $\mathrm{C}=\mathrm{O}$ bond presented in aliphatic and aromatic aldehyde groups $\left(\sim 1690 \mathrm{~cm}^{-1} ; \sim 1737 \mathrm{~cm}^{-1}\right.$; $\left.\sim 1710 \mathrm{~cm}^{-1}\right)$, vibrations of aromatic ring $\left(\sim 1604 \mathrm{~cm}^{-1}\right.$; $1500 \mathrm{~cm}^{-1}$ ); extinction vibrations of $\mathrm{C}-\mathrm{O}$ bonds from phenolic and alcoholic compounds $\left(\sim 1230 \mathrm{~cm}^{-1}\right.$; $\left.\sim 1150 \mathrm{~cm}^{-1} ; \sim 1100 \mathrm{~cm}^{-1}\right)$. Thus the presence of different phenolic and alcoholic groups is validated as main constitutive groups of total flavonoids and polyphenols responsible for the antibacterial action of prepared plant extracts.

FTIR spectra analysis of plant powder samples (before and after solid-liquid extraction)

Overall, the FTIR spectra were registered for all plants powder samples, after and before the alcoholic extraction (after corresponding drying in oven) (Figures 5 and 6). 

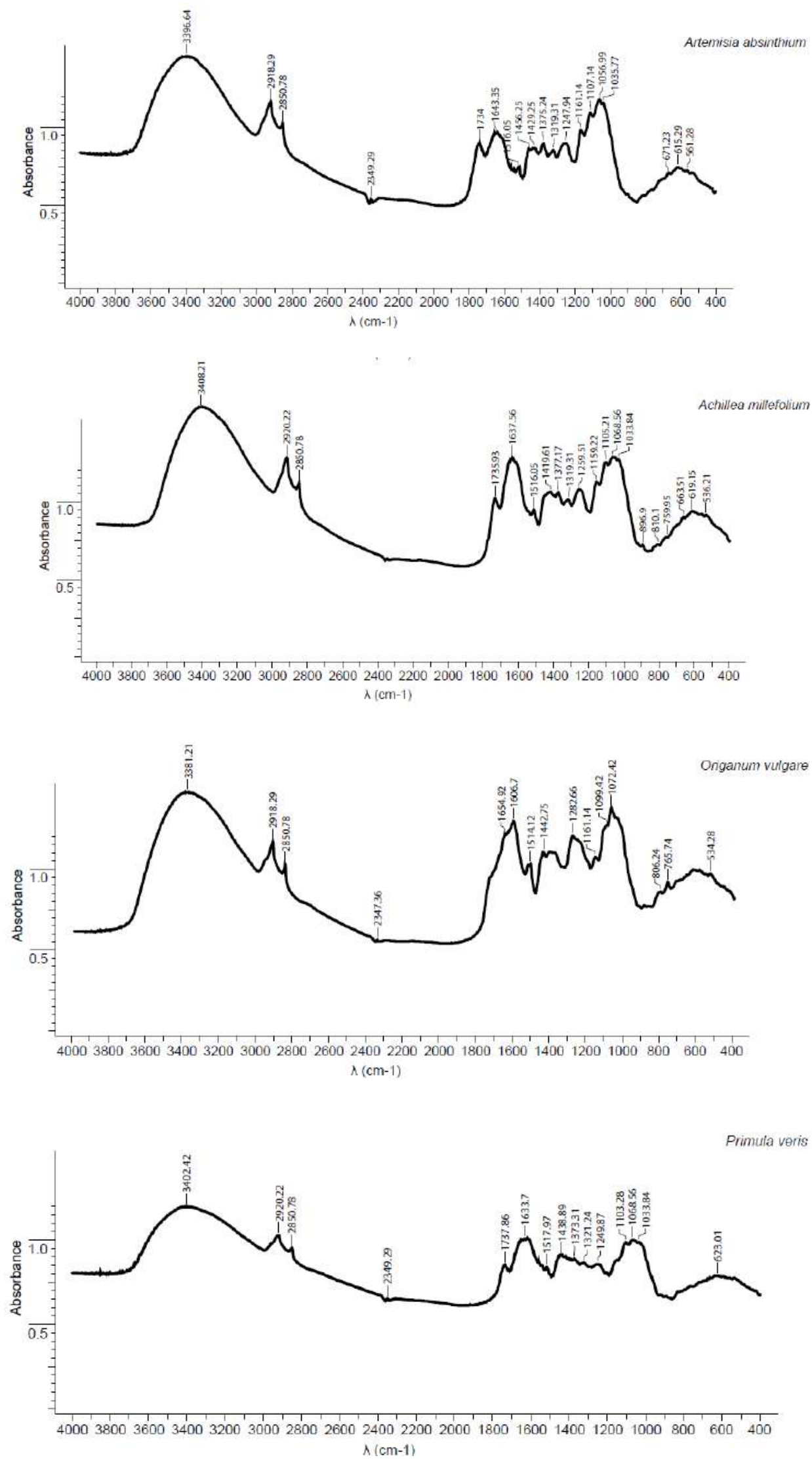

Figure 5. FTIR spectra of dried plant powder samples (Artemisia absinthium, Achillea millefolium, Origanum vulgare, Primula veris) after extraction. 

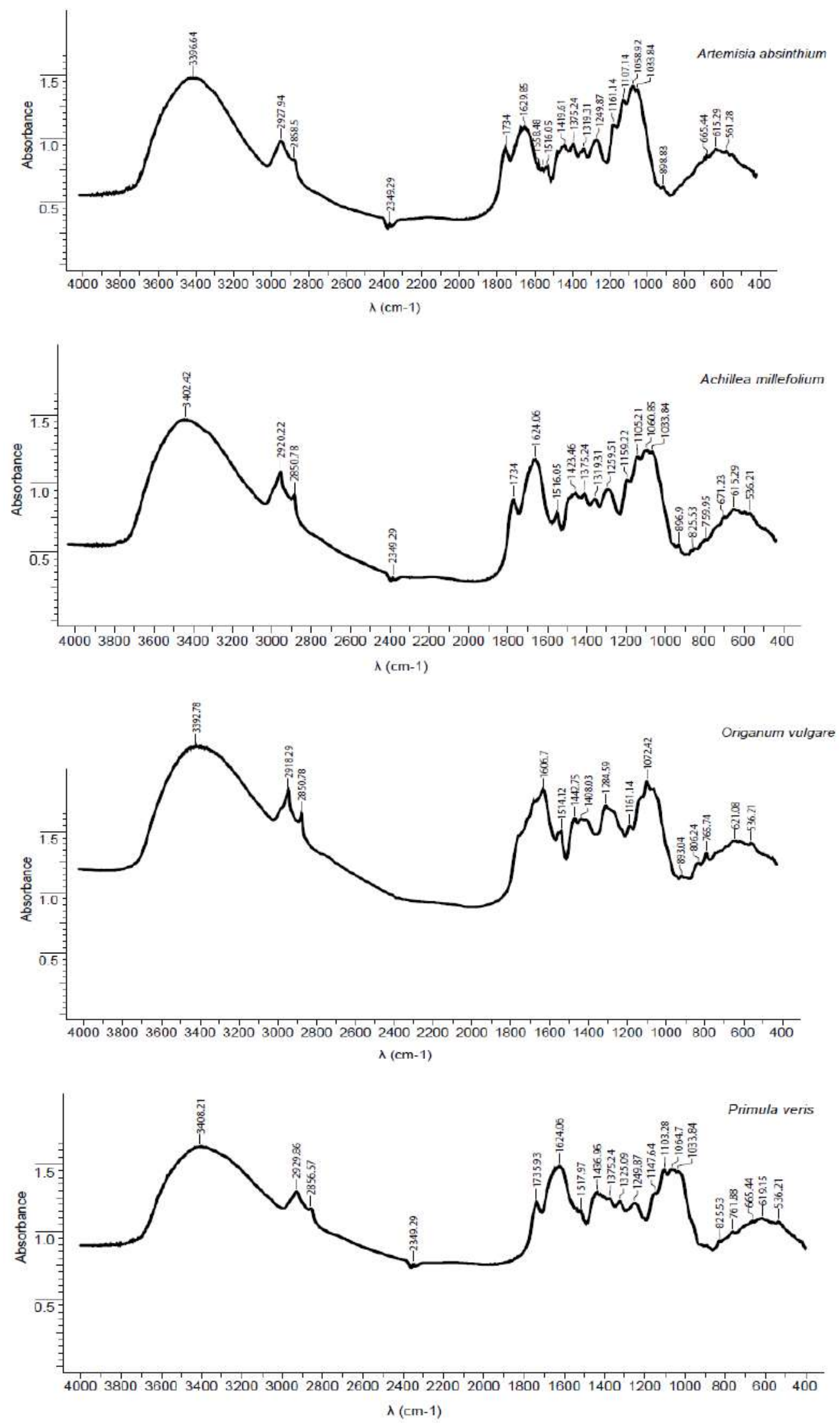

Figure 6. FTIR spectra of dried plant powder samples before alcoholic extraction by Soxhlet heat reflux installation. Artemisia absinthium: phases ratio $=1 / 20$, extraction time $=2 \mathrm{~h}$; Origanum vulgare: phases ratio $=1 / 15$, extraction time $=2 \mathrm{~h} ;$ Achillea millefolium: phases ratio $=1 / 20$, extraction time $=1 \mathrm{~h}$; Primula veris: phases ratio $=1 / 10$, extraction time $=2 \mathrm{~h}$; 
The analysis of these FTIR spectra of plant powder samples, before and after the alcoholic extraction, emphasizes a few small differences, in principal due to the fact that the high amount of celluloses and lignin is dimming any other component of lower concentration (or in traces). Also, for Primula veris an additional absorption peak at $3012 \mathrm{~cm}^{-1}$ appears which can correspond to the extinction vibrations of alcoholic or phenolic groups. Moreover, the vibrations of $\mathrm{C}=\mathrm{O}$ bond presented in aliphatic and aromatic aldehyde/ketone groups ( 1690$1740 \mathrm{~cm}^{-1}$ ) are not presented at Origanum vulgare before extraction and were appeared after extraction $\left(1693 \mathrm{~cm}^{-1}\right)$, but the extinction vibrations of $\mathrm{C}-\mathrm{O}$ bonds from phenolic and alcoholic compounds are abundent in Origanum vulgare $\left(\sim 1228 \mathrm{~cm}^{-1} ; \sim 1165 \mathrm{~cm}^{-1} ; \sim 1116 \mathrm{~cm}^{-1}, 1072\right.$ and $\left.1043 \mathrm{~cm}^{-1}\right)$ related to only two peaks at Artemisia absinthium $\left(\sim 1276 \mathrm{~cm}^{-1}\right.$ and $\left.\sim 1053 \mathrm{~cm}^{-1}\right)$ and Primula veris $\left(\sim 1205 \mathrm{~cm}^{-1}\right.$ and $\left.1064 \mathrm{~cm}^{-1}\right)$, or only one peak at Achillea millefolium $\left(1018 \mathrm{~cm}^{-1}\right)$ (consequence of alcoholic extraction, and also polyphenols and flavonoids presence). The alcoholic extracts of Artemisia absinthium, Achillea millefolium and Primula veris presented distinct peaks corresponding to the vibrations of $\mathrm{C}=\mathrm{O}$ bond in aliphatic and aromatic aldehyde/ketone groups $(\sim 1741, \sim 1710$, $\sim 1620, \sim 1606 \mathrm{~cm}^{-1}$ for Artemisia absinthium, or $\sim 1737$, $\sim 1616 \mathrm{~cm}^{-1}$ for Achillea millefolium, or $\sim 1737, \sim 1714$, $\sim 1654, \sim 1606 \mathrm{~cm}^{-1}$ for Primula veris) (possible consequence of oxidative transformations during and after the heat reflux extraction with ethanol).

Due to the presence of high amounts of flavonoids and polyphenols, these vegetal extracts may have bioinsecticide effects (MOCAN et al, 2018 [3]) on the field of agricultural culture and storage pests which were preliminarily evidentiated in our previous research works and will be clearly described in further reports.

\section{Conclusions}

Alcoholic vegetal extracts were prepared from a series of plants of spontaneous flora: wormwood (Artemisia absinthium), yarrow (Achillea millefolium), oregano (Origanum vulgare) and primrose (Primula veris), collected from Siret Valley, Suceava region (Romania), by using two methods of solid/liquid extraction: alcoholic maceration and heat reflux extraction in the Soxhlet installation. The extraction efficiency (degree of extraction, $\%$ ) of both extraction methods related to the two principal operating parameters: solid/liquid ratio and extraction time was appreciated, and also the determination of total concentration of polyphenols and flavonoids. The results indicated that the extraction by using the Soxhlet heat reflux methodology is preferred. In this case, the solid/ liquid ratio and the extraction time are different in function of the plant type: wormwood (Artemisia absinthi) - $1 \mathrm{~h}$ and $\mathrm{S} / \mathrm{L}$ ratio $=1 / 15$; yarrow (Achillea millefolium) $-2 \mathrm{~h}$ and $\mathrm{S} / \mathrm{L}$ ratio $=1 / 20 ;$ oregano (Origanum vulgare) $-2 \mathrm{~h}$ and $\mathrm{S} / \mathrm{L}$ ratio $=1 / 15$, and primrose (Primula veris) $-2 \mathrm{~h}$ and $\mathrm{S} / \mathrm{L}$ ratio $=1 / 10$. The advanced physical-chemical analysis (UV-Vis and FTIR spectra), the quantitative determinations of the total polyphenols and flavonoids concentration corroborated with our previous work on potential insecticide effect (as biopesticide) conclude that the biological active compounds responsible for this effect may be of flavonoid class. Primrose (Primula veris) was proved to be the plant with the strongest bio-insecticide effects.

\section{References}

1. FIERASCU RC, FIERASCU I, ORTAN A, AVRAMESCU SM, DINU-PIRVU CE, IONESCU D, EL-SHEMY HA (Eds.). Aromatic and Medicinal Plants - Back to Nature, Chapter: Romanian Aromatic and Medicinal Plants: From Tradition to Science, IntechOpen, 2017; 149-173. doi: 10.5772/66513

2. IGNAT I, VOLF I, POPA VI. A critical review of methods for characterisation of polyphenolic compounds in fruits and vegetables. Food Chemistry, 2011; 126: 1821-1835. doi: 10.1016/j.foodchem.2010.12.026

3. MOCAN A, ZENGIN G, MOLLICA A, UYSAL A, GUNES E, CRIŞAN G, AKTUMSEK A. Biological effects and chemical characterization of Iris schachtii Markgr. extracts: A new source of bioactive constituents. Food and Chemical Toxicology, 2018; 112: 448-457. doi: 10.1016/j.fct.2017.08.004

4. PRUTEANU A, POPESCU C, VLADUT V, GAGEANU G. Biochemical analysis of some vegetal extracts obtained from indigenous spontaneous species of Thymus serpyllum L. Romanian Biotechnological Letters, 2018; 23(5): 14013-14024. doi: 10.26327/ RBL2018.179

5. BRZOZOWSKI L, MAZOUREK M. Sustainable agricultural future relies on the transition to organic agroecological pest management. Sustainability, 2018; 10: 2023-2048. doi: 10.3390/su10062023

6. CHANDLER D, BAILEY AS, TATCHELL GM, DAVIDSON G, GREAVES J, GRANT WP. The development, regulation and use of biopesticides for integrated pest management. Philosophical Transactions of the Royal Society of London B Biological Sciences, 2011; 366 (1573): 1987-1998. doi: 10.1098/ rstb.2010.0390

7. DAYAN FE, CANTRELL CL, DUKE SO. Natural products in crop protection. Bioorganic \& Medicinal 
Chemistry, 2009; 17: 4022-4034. doi: 10.1016/j.bmc. 2009.01.046

8. GILL HK, GARG H. Pesticide-Toxic Effects, in: Larramendy M.L., Soloneski S. (Eds.), Pesticides: Environmental Impacts and Management Strategies, IntechOpen, Rijeka, Croatia, 2014; 187-230.

9. GUPTA S, DIKSHIT AK. Biopesticides: An ecofriendly approach for pest control. Journal of Biopesticides, 2010; 3: 186-188.

10. MAZID S, KALITA JC, RAJKHOWA RC. A review on the use of biopesticides in insect pest management. International Journal of Science and Advanced Technology, 2011; 1(7): 169-178.

11. DARABAN G, BADEANU M, RUSU L, SUTEU D. Researches on the biopesticides obtained by extraction with non-toxic solvents and the insecticide effect on deposit pests. Bull. IPI., Iasi (Romania), 2018; 64(68) (2): 33-41.

12. DARABAN G, BADEANU M, RUSU L, SUTEU D. Biopesticides a new challenge in assuring food quality and sustainable agriculture, Lucrari Stiintifice, Seria Horticultura, USAMV - Iasi, 2018; 61(1): 269-274.

13. DARABAN G., BADEANU M, RUSU L, ZAHARIA C, SUTEU D. Vegetal extract from spontaneous Romanian flora with bioinsecticidal action, Research Journal of Agricultural Science, 2020; 52 (4): 183-188.

14. PAVUN L, USKOKOVIC-MARKOVIC S, JELIKICSTANKOV M, ĐIKANOVIC D, ĐURDEVIC P. Determination of Flavonoids and Total Polyphenol Contents in Commercial Apple Juices. Czech Journal of Food Sciences, 2018; 36(3): 233-238. doi: 10.17221/ 211/2017-CJFS
15. TATARU-FARMUS RE, SIMINICEANU I, BOUALLOU C. Carbon dioxide absorption into new formulated amine solutions (I). Solution viscosity measuring and correlation. Chemical Engineering Transactions, 2007; 12:175-181.

16. SHEN S, YANG Y, WANG Y, REN S, HAN J, CHEN A. $\mathrm{CO}_{2}$ absorption into aqueous potassium salts of lysine and proline: density, viscosity and solubility of $\mathrm{CO}_{2}$. Fluid Phase Equilibria, 2015; 399: 40-49. doi: 10.1016/j.fluid.2015.04.021

17. BRUCE AB (Ed.). Introduction to Flavonoids. Chapter 4: Extraction, Purification and Identification of Flavonoids, Harwood Academic Publishers, Amsterdam, The Nederland, 1998; 175-242.

18. SPIRIDON I, BODIRLAU R, TEACA AA. Total phenolic content and antioxidant activity of plants used in traditional Romanian herbal medicine. Central European Journal of Biology, 2011; 6(3): 388-396. doi:10.2478/s11535-011-0028-6

19. HARNLY JM, ZE LIN L, BHAGWAT S. Profiling methods for the determination of phenolic compounds in foods and dietary supplements. Analytical and Bioanalytical Chemistry, 2007; 389(1): 47-61. doi: 10.1007/s00216-007-1424-7

20. ALEIXANDRE-TUDO JL, DU TOIT W, SOLISOVIEDO RL (Eds.). Frontiers and New Trends in the Science of Fermented Food and Beverages. Chapter: The Role of UV-Visible Spectroscopy for Phenolic Compounds Quantification in Winemaking, IntechOpen, Rijeka, Croatia, 2019; 1-21. 